\title{
Redescription on Raillietina echinobothrida (Pasquale, 1890) (Cestoda: Davaineidae) and Study of Conserved Domain across Divergent Phylogenetic Lineages of Class Cestoda Somnath Waghmare ${ }^{1}$, Sherkhane $\mathrm{AS}^{2}$, Ramrao Chavan ${ }^{3}$ and Virendra Gomase ${ }^{4 *}$
}

${ }^{1}$ Department of Zoology, Nowrosjee Wadia College of Arts and Science, India

${ }^{2}$ The Global Open University, Nagaland, India

${ }^{3}$ Department of Zoology, Dr Babasaheb Ambedkar Marathwada University, India

${ }^{4}$ Department of CS and IT, Dr Babasaheb Ambedkar Marathwada University, India

\begin{abstract}
Raillietina (Fuhrmannetaa) echinobothrida, (Magnin, 1881) cestode parasite of Gallus gallus domesticus is redescribed on the basis of type material from Aurangabad, Marathawada, Maharashtra, India. The present worms resemble with R. echinobothrida, (Magnin, 1881) in having all essential morphological characters. having scolex oval, rostellum elongated/rounded, presence of four suckers, short neck, mature proglottids are broader than long, testes rounded and excretory canal long tube. But the same differ due to number of testes. Hence it is redescribed. We carried out the phylogenetic analyses to observe molecular resemble of related proteins.
\end{abstract}

Keywords: R. (Fuhrmannetaa) echinobothrida; Magnin, 1881; Gallus gallus domesticus; MSA; Conserve domain; Phylogenetic analysis

\section{Introduction}

Raillietina echinobothrida is a endoparasite, and this tapeworm belonging to the class Cestoda. This is avian gastrointestinal parasite of family Davaineidae (Cestoda: Cyclophyllidea), and is the most pathogenic and prevalent species infecting Gallus domesticus Linnaeus, 1758. R. echinobothrida requires two hosts, birds and ants, for completion of its life cycle. $R$. echinobothrida is a hermaphrodite worm having both the male and female reproductive organs in its body. The parasite is responsible for 'nodular tapeworm disease' in poultry [1,2]. This tapeworm is responsible for stunted growth of young chicken, also emaciation of adult and decreased egg production of hen. R. echinobothrida does not cause gross pathological damages, but in severe lesions on the intestinal walls and diarrhoea could arise. It ostensibly resulted in ill health [3]. Phylogenetic analyses have become essential to research on R. echinobothrida for the evolutionary tree of life. It shows taxonomical classification, identification, and naming of organisms, which is usually richly informed by phylogenetics. Multiple sequence alignments are the resource for the annotation of functional units in proteins called as conserved domain. This Conserved domains can be thought of as distinct functional, structural units of a protein from R. echinobothrida. In molecular evolution of R. echinobothrida such domains may have been utilized as building blocks, and may have been recombined in different arrangements to modulate protein function, which can be determined by sequence and structure analysis $[4,5]$.

\section{Material and Methods}

\section{Study cestode}

Sixty five cestode were collected from the intestine of Gallus gallus domesticus from Aurangabad district Maharashtra state, India, during the period Dec-2006 to Dec-2009. Thirty cestode were preserved in hot $4 \%$ formalin and specimen were stained with Haris Haematoxyline and Borax carmine stain and passed through various alcoholic grades. Cleared in xylene, mounted in DPX and drawing are made with aid of camera lucida. All measurements are given in the millimetre [6,7].

\section{Sources and sequence information of Cestoda class}

We have taken seven species of Cestoda class, in which targeted is nucleotide-binding domain of the sugar kinase/HSP70/actin protein data were used to observe molecular resemble of related protein by phylogenic analysis $[8,9]$.

\section{Multiple sequence alignment of Cestoda class}

Multiple sequence alignment [MSA] is conducted by COBALT that aligns protein sequences of similar Cestoda class using a combination of distance matrix and approximate parsimony methods. Numerical setting method is used to study the relative entropy threshold, in bits, that must be met for an alignment column to be displayed in red. A larger number indicates higher degree of conservation. The relative entropy is computed as:

\section{$\sum_{i} f_{i} \log _{2}\left(f_{i} / p_{i}\right)$,}

where $i$ is residue type, $f_{i}$ is residue frequency observed in the multiple alignment column, and $p_{i}$ is the background residue frequency.

Identity setting used for only columns with one residue type will be colored in red [10,11].

\section{Construction of a phylogenetic tree for actin protein}

Phylogenetic analyses were performed by Fast minimum evolution algorithm and Neighbor Joining algorithms to allow the reconstruction phylogenetic tree of the molecular evolutionary history of various

*Corresponding author: Virendra Gomase, Department of CS and IT, Dr Babasaheb Ambedkar Marathwada University, India, Tel \& Fax: +91-22-26722289; E-mail: drsomnathwaghmare@gmail.com

Received May 09, 2014; Accepted July 28, 2014; Published July 30, 2014

Citation: Waghmare S, Sherkhane AS, Chavan R, Gomase V (2014) Redescription on Raillietina echinobothrida (Pasquale, 1890) (Cestoda: Davaineidae) and Study of Conserved Domain across Divergent Phylogenetic Lineages of Class Cestoda. J Veterinar Sci Technol 5: 187. doi:10.4172/2157-7579.1000187

Copyright: (C 2014 Waghmare S, et al. This is an open-access article distributed under the terms of the Creative Commons Attribution License, which permits unrestricted use, distribution, and reproduction in any medium, provided the original author and source are credited. 
Citation: Waghmare S, Sherkhane AS, Chavan R, Gomase V (2014) Redescription on Raillietina echinobothrida (Pasquale, 1890) (Cestoda: Davaineidae) and Study of Conserved Domain across Divergent Phylogenetic Lineages of Class Cestoda. J Veterinar Sci Technol 5: 187. doi:10.4172/2157-7579.1000187

Page 2 of 5

aligned sequences that are useful to align highly evolved gene families clearing evolutionary relationships such as multiple actin proteins $[12,13]$. Trees were obtained by the methods Fast minimum evolution algorithm and Neighbor Joining algorithms. Evolutionary distance is studied by Grishin (protein) model $[14,15]$ and distance between two sequences modelled as expected fraction of amino acid substitutions per site given the fraction of mismatched amino acids in the aligned region and can be computed for fraction of mismatched amino acids larger than $0.75[5,3]$

\section{Results and Description}

\section{Observation of R. echinobothrida}

In R. echinobothrida, the scolex is having four rounded sucker which overlaps each other and measures 0.242 (0.1619-0.3155) in length and $0.1262(0.0970-0.1553)$ in width. The mature proglottids are 2-3 times broader than long and measures 0.4563 (0.4271-0.4854) in length and 0.9805 (0.9028-1.0581) in width. Testes are oval to rounded, 20-25 in number and measures 0.0291 in diameter. Cirrus pouch is elongated in shape, preovarian, situated in centre of proglottids and measures 0.1262 (0.1067-0.1456) in length and $0.0436(0.0339-0.0533)$ in width. The vas deference is long, curved tube and measures 0.2621 (0.2524-0.2766) in length and $0.0097(0.0048-0.0145)$ in width. The gravid segments are broader than long and contain numerous egg capsules. Each egg capsule contains 4-5 eggs (Figures 1 and 2).

\section{Systematic position}

Raillietina (Fuhrmannetta) echinobothrida

$\begin{array}{ll}\text { Class: } & \text { Eucestoda } \\ \text { Order: } & \text { Davaineidea } \\ \text { Family: } & \text { Davaneidae } \\ \text { Genus: } & \text { Raillietina } \\ \text { Species: } & \text { Raillietina echinobothrida }\end{array}$

\section{Taxonomy summary}

Type species: Raillietina (Fuhrmannetta) echinobothrida

Host: Gallus gallus domesticus

Habitat: Intestine

Locality: Aurangabad M.S., India

Period of collection: Dec. 2006-Dec.2009

Deposition: Helminthology Research Lab, Dept. Of Zoology, Dr. Babasaheb AmbedkarMarathawada University, Aurangabad.

\section{Evolutionary distance}

This study, $7 \beta$-actin from Cestoda class is summarized to study the evolutionary distance. The identification of the origin of $\beta$-actin protein, multiple sequences analysis, observing the conserved amino acid residues and reconstruct the phylogenetic tree specify the evolutionary history, relationship of Cestoda with different species
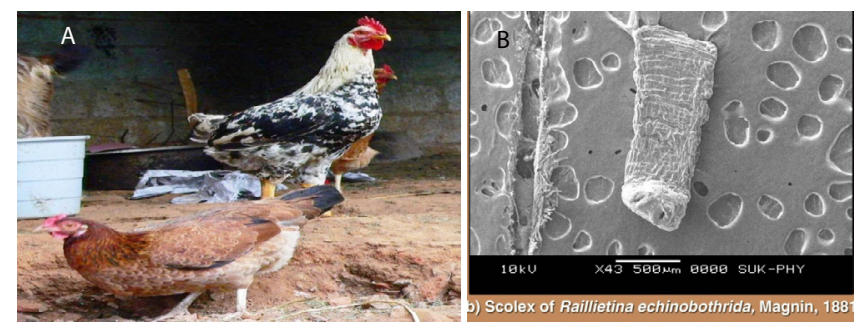

Figure 1: Host Gallus gallus domesticus, 1b-SEM image of scolex of $R$. (Fuhrmannetta) echinobothrida.
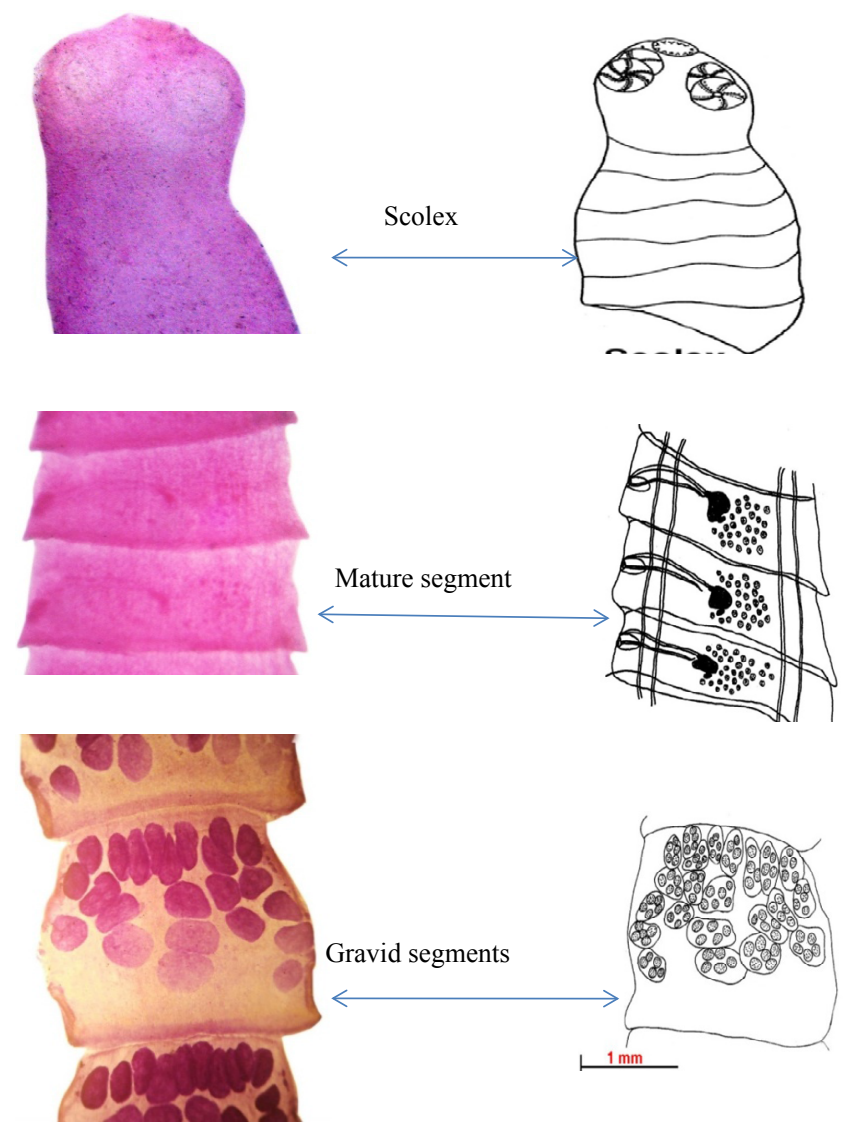

Figure 2: Scolex, mature segment and gravid segments of $R$. (Fuhrmannetta) echinobothrida.

\begin{tabular}{|c|c|c|c|c|c|c|}
\hline Accession & Species Name & Max score & Total score & Query cover & E value & Ident \\
\hline AGA19608.1 & $\beta$-actin [Raillietina echinobothrida] & 235 & 235 & $100 \%$ & 2.00E-77 & $100 \%$ \\
\hline ERG81274.1 & actin-2 [Ascaris suum] & 176 & 176 & $78 \%$ & $3.00 \mathrm{E}-53$ & $93 \%$ \\
\hline BAI81968.1 & actin [Nippostrongylus brasiliensis] & 174 & 174 & $75 \%$ & $3.00 \mathrm{E}-53$ & $96 \%$ \\
\hline ACP21243.1 & actin II [Echinococcus granulosus] & 172 & 172 & $75 \%$ & $4.00 E-53$ & $96 \%$ \\
\hline EJW72694.1 & actin-2 [Wuchereria bancrofti] & 174 & 174 & $75 \%$ & $5.00 \mathrm{E}-53$ & $96 \%$ \\
\hline ABN14926.1 & cytoskeletal actin 2 [Taenia asiatica] & 174 & 174 & $74 \%$ & $6.00 \mathrm{E}-53$ & $98 \%$ \\
\hline BAJ07368.1 & actin [Taenia taeniaeformis] & 174 & 174 & $75 \%$ & $8.00 E-53$ & $96 \%$ \\
\hline
\end{tabular}

Table 1: Sequences producing significant alignments. 
Citation: Waghmare S, Sherkhane AS, Chavan R, Gomase V (2014) Redescription on Raillietina echinobothrida (Pasquale, 1890) (Cestoda: Davaineidae) and Study of Conserved Domain across Divergent Phylogenetic Lineages of Class Cestoda. J Veterinar Sci Technol 5: 187. doi:10.4172/2157-7579.1000187

Page 3 of 5

(Table 1). Rectangle tree shows rectangular shaped rooted tree, where root is places in the longest edge. Fast minimum evolution algorithm produce un-rooted tree such as ones shown as radial or force in the tabs below. The rooted trees are created by placing a root in the middle of the longest edge (Figure 3). Slanted tree shows similar to rectangle, but with triangular tree shape. Neighbor Joining algorithms produce unrooted tree such as ones shown as radial or force in the tabs below. The rooted trees are created by placing a root in the middle of the longest edge (Figure 4).

\section{Multiple sequence alignment}

Multiple sequence alignment analysis shows columns with no gaps are colour in blue or red. The red colour indicates highly conserved regions and blue indicates less conserved ones. The Conservation analysis can be used to select a threshold for determining which columns is colour in red (Figure 5). Multiple sequence alignment identify conserved motifs and to predict functional role in the variable sites as well as conserved sites show the sequence divergence profile

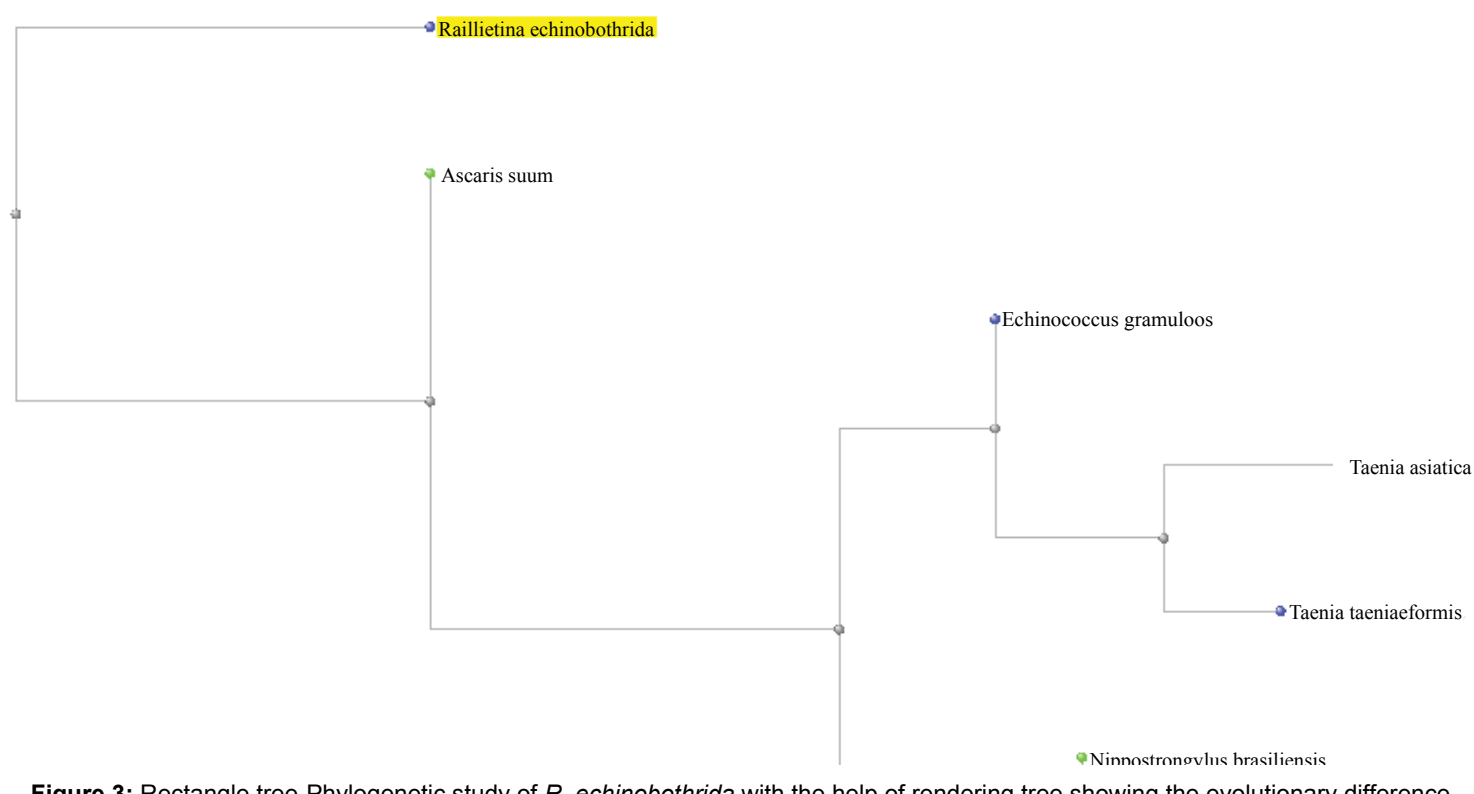

Figure 3: Rectangle tree-Phylogenetic study of $R$. echinobothrida with the help of rendering tree showing the evolutionary difference.

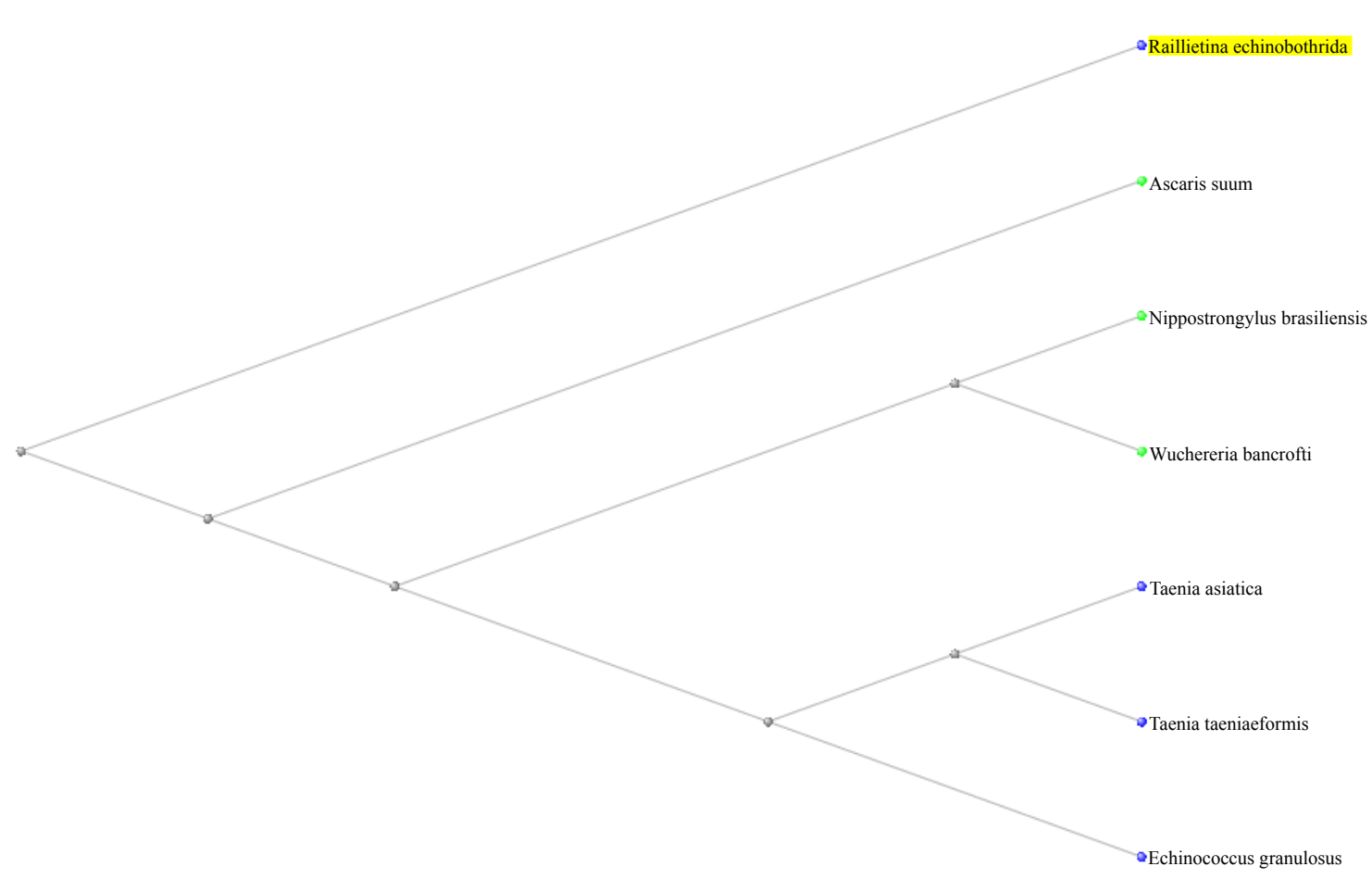

Figure 4: Slanted tree-Grishin (protein) model-Phylogenetic study of $R$. echinobothrida with the help of rendering tree. 
Citation: Waghmare S, Sherkhane AS, Chavan R, Gomase V (2014) Redescription on Raillietina echinobothrida (Pasquale, 1890) (Cestoda: Davaineidae) and Study of Conserved Domain across Divergent Phylogenetic Lineages of Class Cestoda. J Veterinar Sci Technol 5: 187. doi:10.4172/2157-7579.1000187

Page 4 of 5

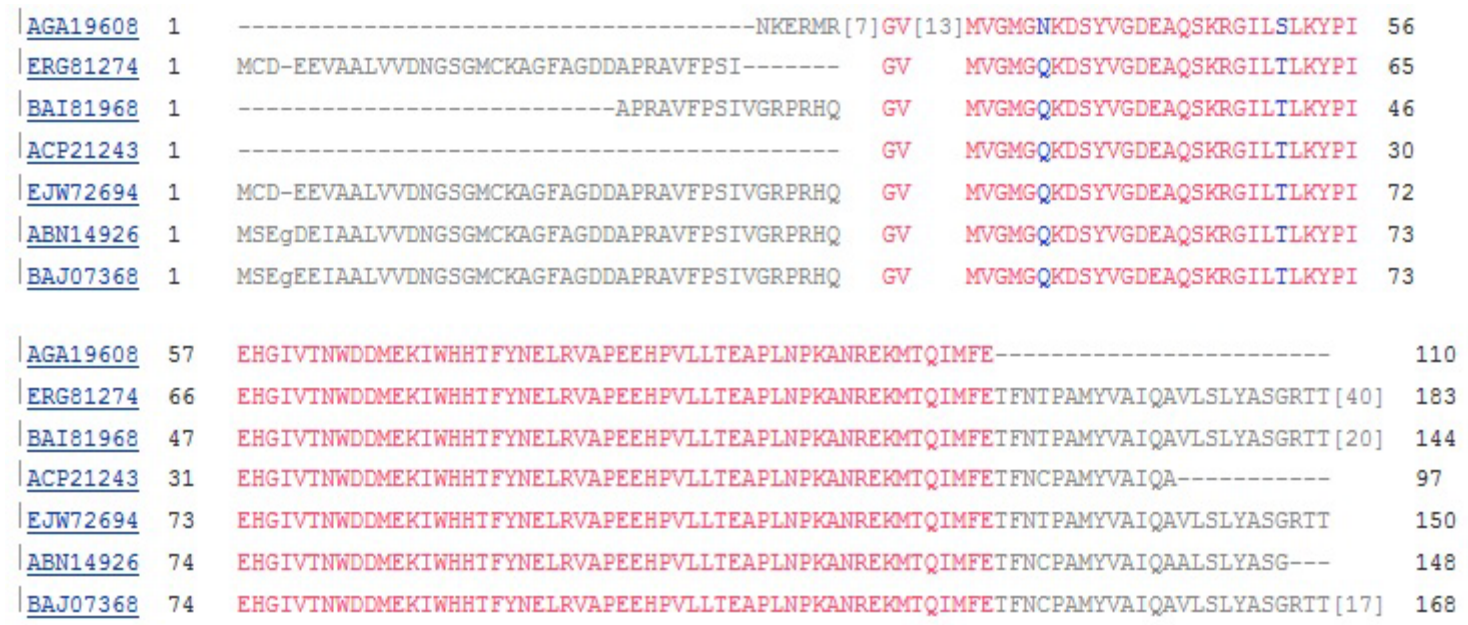

Figure 5: Multiple sequence alignment by COBALT of various Cestoda class species. An alignment will display the following symbols denoting the degree of conservation observed in each column. '*' indicate that, the residues in that column are identical in all sequences in the alignment 12 is $12.50 \%$. ':' indicate that strongly similar, conserved substitutions have been observed, 4 is $4.17 \%$. '.' indicate that weakly similar, semi-conserved substitutions are observed 1 is $1.04 \%$.

Query seq.
Specific hits
Superfanilies

Figure 6: Conserved domain analysis shows nucleotide-binding domain of the sugar kinase/HSP70/actin superfamily.

of these actin proteins, which demonstrate the sequence enrichment strategy of these sequences for adaptation to different physiological systems. Here we observed that from all sequences of actin proteins that Cys, Lys, Asp, (Hydrophilic amino acid) Pro, Gly, (hydrophobic amino acid) which is conserved in all peptides having a common ancestor. That all of these peptides share eight highly conserved cysteine, which were involved in the formation of $\beta$-strands are almost conserved. Cysteine $(\mathrm{C})$ is conserved in all sequences at 8 sites.

\section{Conserved domain analysis}

Molecular study of Cestoda class species shows one conserved domain is nucleotide-binding domain of the sugar kinase/HSP70/actin superfamily. The nucleotide-binding region residues are conserved and the nucleotide sits in a deep cleft formed between the two lobes of the nucleotide-binding domain (NBD). Substrate binding to superfamily members is associated with closure of this catalytic site cleft. Functional activities of nucleotide-binding domain, including hexokinases, actin, and HSP70s, are modulated by allosteric effectors, which may act on the cleft closure (Figure 6).

\section{Conclusion}

The presences of various species of the Cestoda were noted on the basis of actual sighting. Above survey with the primary objective of collecting and identifying the species, Sampling for estimation population of available species and understanding the community structure of amphibians in different habitat types. Phylogenetic analysis of Cestoda class signifies that nucleotide-binding domain of the sugar kinase protein is important components of Cestoda species, are originated from proteins enriched with different sequence specific substitution strategy for biological needs. Comparative analyses specify that the nucleotide-binding domain of the sugar kinase protein demonstrates how proteins are generated within the nature's testing ground for tailor-made biologic needs. Tracing the natural protein engineering scheme of sodium/calcium exchanger protein enrich our knowledge which in turn helps to molecular phylogeny.

\section{Acknowledgement}

Authors are thankful to Department of Zoology, Department of CS and IT, Dr Babasaheb Ambedkar Marathwada University, Aurangabad, India; Principal, Nowrosjee Wadia College of Arts and Science, Pune, India for providing the necessary facilities for research.

\section{References}

1. Challam M, Roy B, Tandon V (2010) Effect of Lysimachia ramosa (Primulaceae) on helminth parasites: motility, mortality and scanning electron microscopic observations on surface topography. Vet Parasitol 169: 214-218.

2. Bâ CT, Sene T, Marchand B (1995) Scanning electron microscope examination of scale-like spines on the rostellumm of five Davaineinae (Cestoda, Cyclophyllidea). Parasite 2: 63-67.

3. Waghmare S, Waghmare D, Bhatnagar PS (2013) Species Diversity of Short Horned Grasshopper (Orthoptera: Acrididae) in Selected Grasslands of Solapur District, Maharashtra, India. J Biodivers Endanger Species 1:110.

4. Gomase VS, Kale KV, Tagore S, Hatture SR (2008) Proteomics: technologies for protein analysis. Curr Drug Metab 9: 213-220.

5. Gomase VS, Tagore S (2009) Phylogenomics: evolution and genomics intersection. Int J Bioinform Res Appl 5: 548-563.

6. Lalchhandama K (2010) In vitro Effects of Albendazole on Raillietina echinobothrida, the Cestode of Chicken, Gallus domesticus. J Young Pharm 2: $374-378$.

7. Mukaratirwa S, Hove T (2009) A survey of ectoparasites, cestodes and management of free-range indigenous chickens in rural Zimbabwe. J S Afr Vet Assoc 80: 188-191.

8. The National Center for Biotechnology Information advances science and health by providing access to biomedical and genomic information. 
Citation: Waghmare S, Sherkhane AS, Chavan R, Gomase V (2014) Redescription on Raillietina echinobothrida (Pasquale, 1890) (Cestoda: Davaineidae) and Study of Conserved Domain across Divergent Phylogenetic Lineages of Class Cestoda. J Veterinar Sci Technol 5: 187. doi:10.4172/2157-7579.1000187

9. Sayers EW, Barrett T, Benson DA, Bolton E, Bryant SH, et al. (2012) Database resources of the National Center for Biotechnology Information. Nucleic Acids Res 40: D13-25.

10. Papadopoulos JS, Agarwala R (2007) COBALT: constraint-based alignment tool for multiple protein sequences. Bioinformatics 23: 1073-1079.

11. Gomase VS, Chitlange NR, Changbhale SS, Kale KV (2013) Prediction of Brugia malayi antigenic peptides: candidates for synthetic vaccine design against lymphatic filariasis. Protein Pept Lett 20: 864-887.

12. Desper R, Gascuel O (2004) Theoretical foundation of the balanced minimum evolution method of phylogenetic inference and its relationship to weighted least-squares tree fitting. Mol Biol Evol 21: 587-598.

13. Saitou N, Nei M (1987) The neighbor-joining method: a new method for reconstructing phylogenetic trees. Mol Biol Evol 4: 406-425.

14. Grishin NV (1995a) Approximates the same model as Kimura, but can be computed for fraction of mismatched amino acids larger than 0.75 . J Mol Evol 41:675-79. PMID: 18345592

15. Grishin NV(1995b) More general evolutionary model: substitution rates vary for both amino acids and sites. J Mol Evol 41:675-79. PMID: 18345592. 